\title{
Osteopontin promotes dendritic cell maturation and function in response to $\mathrm{HBV}$ antigens
}

\author{
This article was published in the following Dove Press journal: \\ Drug Design, Development and Therapy \\ 12 June 2015 \\ Number of times this article has been viewed
}

\author{
Guangying Cui ${ }^{1,2}$ \\ Jianing Chen ${ }^{1,2}$ \\ Jianqin $\mathrm{He}^{1,2}$ \\ Chong Lu ${ }^{1,2}$ \\ Yingfeng $\mathrm{Wei}^{1,2}$ \\ Lin Wang ${ }^{1,2}$ \\ Xuejun $\mathrm{Xu}^{3}$ \\ Lanjuan $\mathrm{Li}^{1,2}$ \\ Toshimitsu Uede ${ }^{4}$ \\ Hongyan Diao ${ }^{1,2}$
}

'State Key Laboratory for Diagnosis and Treatment of Infectious Diseases, the First Affiliated Hospital, School of Medicine, Zhejiang University, Hangzhou, Zhejiang, ${ }^{2}$ Collaborative Innovation Center for Diagnosis and Treatment of Infectious Diseases, Hangzhou, ${ }^{3}$ Department of Oral Orthodontics, Affiliated Stomatology Hospital, School of Medicine, Zhejiang University, Hangzhou, Zhejiang, People's Republic of China; 'Molecular Immunology, Institute for Genetic Medicine, Hokkaido University, Sapporo, Japan
Correspondence: Hongyan Diao State Key Laboratory for Diagnosis and Treatment of Infectious Diseases, the First Affiliated Hospital, School of Medicine, Zhejiang University, Hangzhou, Zhejiang 310003, People's Republic of China

Tel/fax +86 57/ 87236446

Email diaohy@zju.edu.cn
Purpose: Dendritic cells (DCs) play critical roles in promoting innate and adaptive immunity in microbial infection. Functional impairment of DCs may mediate the suppression of viralspecific T-cell immune response in chronic hepatitis B (CHB) patients. Osteopontin (OPN) is involved in several liver diseases and infectious diseases. However, whether OPN affects DC function in hepatitis B virus (HBV) infection is unknown.

Methods: Twenty CHB patients and 20 healthy volunteers were recruited. OPN secreted by DCs was compared. Peripheral blood mononuclear cells cultured with OPN antibody were examined to study the costimulatory molecular expression and interleukin (IL)-12 production of DCs after HBV antigenic stimulation. OPN-deficient mice were used to investigate the influence of OPN on DC maturation and function after HBV antigenic stimulation in vitro and in vivo. Exogenous OPN was administrated to further verify the functioning of DCs from CHB patients upon HBV antigenic stimulation.

Results: We found that OPN production of DCs from CHB patients was significantly lower than those from healthy volunteers. The absence of OPN impaired IL-12 production and costimulatory molecular expression of DCs upon stimulation with HBV antigens. Defective DC function led to reduced activation of Th1 response to HBV antigens. In addition, OPN deficiency in DCs reduced the HBV antigen-induced inflammatory response in the liver of mice. Importantly, OPN administration significantly promoted the maturation of DCs from CHB patients in vitro.

Conclusion: These findings suggested that OPN could improve the maturation and functioning of DCs in the immune response to HBV antigens, which might be useful to further improve the effect of DC vaccine.

Keywords: osteopontin, dendritic cells, hepatitis B virus

\section{Introduction}

Hepatitis B virus (HBV) infection remains an important public health problem and adversely affects human health worldwide. There are about 240 million people living with chronic HBV infection. ${ }^{1} \mathrm{HBV}$ infection leads to a broad spectrum of clinical manifestations, including fulminant hepatic failure, cirrhosis, and hepatocellular carcinoma (HCC). It is widely accepted that the adaptive immune responses, particularly the cellular immune response, mediate clearance of $\mathrm{HBV}^{2}$ and that chronic $\mathrm{HBV}$ infection results from an ineffective immune response toward the virus. ${ }^{3}$ However, the exact mechanisms by which some chronic HBV-infected individuals are unable to produce an effective immune response and allow the virus to replicate for long periods in their liver are unclear.

Previous studies have suggested that the functional impairment of dendritic cells (DCs) may mediate the suppression of Th1 cell responses in chronic HBV infection, resulting in viral persistence via reduced interleukin (IL)-12 production by DCs and decreased 
expressions of the costimulatory molecules CD80 and CD86 of mature DC from HBV patients. ${ }^{4-7}$ In general, the immune system can evoke a series of responses to eradicate viral attack immediately following viral infection. Recognition by DCs is considered as the initial response to viral infection, followed by the production of cytokines such as IL-12 and adaptive immune activation and regulation of the infectious process. ${ }^{8}$ The production of IL-12 by DCs is a powerful signal for the generation of Th1 cells, which secrete interferon (IFN)- $\gamma$ and tumor necrosis factor (TNF)- $\alpha$ and mediate cellular immunity to viruses, ${ }^{9-13}$ whereas deficiency in IL-12 production by DCs is a polarizing signal for the generation of Th2 cells, which secrete IL-4 and IL-10 and promote humoral immunity to multicellular pathogens, such as parasitic nematode worms. ${ }^{9-13}$ Meanwhile, the increase of IL-4 level can induce the generation of Th2 cells in a positive feedback loop and inhibit the generation of Th1 cells. ${ }^{11,14}$ In turn, the generation of Th1 can prevent the generation of Th2 cells. ${ }^{15}$ Moreover, as costimulatory molecules and maturation markers, ${ }^{16} \mathrm{CD} 80$ and CD86 can assist major histocompatibility complex (MHC)-II to present antigens and activate T-cells, thereby playing a critical role in defending pathogen infection. ${ }^{17,18}$ In HBV infection, DCs also play an important role and influence the activation of T-cells via antigen presentation and cytokines secretion by mature DCs. ${ }^{8,19}$ Several studies have shown that hepatitis B virus surface antigen (HBsAg)-pulsed DC vaccine can efficiently suppress HBV replication in chronic hepatitis B (CHB) patients. ${ }^{20-22}$ However, the generation of a more functional DC vaccine for efficient therapy of $\mathrm{CHB}$ remains a challenge. ${ }^{22}$

Osteopontin (OPN) is known not only as an extracellular matrix protein, supporting adhesion and migration of inflammatory cells, but also as an immunoregulatory cytokine with a possible role in the development of several inflammatory diseases. ${ }^{23,24}$ A previous study reported that DCs treated with anti-OPN antibody ( $\mathrm{Ab})$ easily underwent apoptosis and expressed lower levels of costimulatory molecules. ${ }^{25}$ Furthermore, OPN expression in DCs regulated the type and intensity of experimental autoimmune encephalomyelitis (EAE) by influencing the expression of type I interferon receptor (IFNAR) on DCs. ${ }^{26}$ In addition, recent studies have indicated that OPN is involved in various liver diseases such as hepatitis, HCC, and cirrhosis..$^{23,27,28}$ In CHB infection, it has been reported that the DC function is impaired. ${ }^{4-7}$ However, it is not known whether OPN directly interferes with DC function in HBV infection. In this study, we found a decreased production of OPN by DCs in CHB patients. OPN deficiency could induce immaturity and impaired cytokine secretory function in DCs, resulting in a low Th1 response to HBV antigens. More importantly, OPN treatment significantly induced the maturation of DCs from CHB patients upon stimulation with $\mathrm{HBV}$ antigens in vitro. These findings suggested that OPN might affect T-cell polarization through DCs, and OPN might be useful to enhance the effect of DC vaccine.

\section{Materials and methods Patients}

A total of 20 patients with $\mathrm{HBeAg}$-positive $\mathrm{CHB}$ (10 men and 10 women; $31.9 \pm 1.9$ years of age) were recruited in the study. In these patients, the total serum bilirubin was $<171 \mu \mathrm{M}$ and prothrombin time activity was $>40 \%$. Besides, the diagnosis standard of CHB infection was based on clinical and biochemical features of the patients. ${ }^{29}$ None of the patients had received anti-HBV therapy before. The average serum HBV DNA of the subjects was $7.9 \pm 0.2 \log 10$ copies $/ \mathrm{mL}$, and the serum alanine aminotransferase (ALT) was $174.97 \pm 26.73 \mathrm{U} / \mathrm{L}$ (the normal range of ALT: 0-40 U/L). Patients were excluded if they had any causes of liver disease other than HBV infection, such as hepatitis $\mathrm{C}$ virus (HCV), human immunodeficiency virus (HIV), or HCC. Additionally, 20 healthy volunteers (10 men and 10 women; $30.3 \pm 1.2$ years of age) with normal ALT level, negative HBsAg, and nondetected HBV DNA served as healthy controls (HCs). Written informed consent was obtained from all subjects prior to sample collection. The study protocol and consent form were approved by the Ethics Committee of the First Affiliated Hospital, School of Medicine, Zhejiang University (Ref No 2014-331).

\section{Mice}

Specific pathogen-free (SPF) male C57BL/6 (B6) (6-weekold) mice were purchased from the Laboratory Animal Center of Shanghai SLRC Experimental Animal Company Ltd. (Shanghai, People's Republic of China). OPN-deficient $\left(\mathrm{OPN}^{-/}\right)$mice backcrossed 11 times to $\mathrm{B} 6$ mice were purchased from Jackson laboratory (Bar Harbor, Maine, USA). All mice were housed at the SPF Laboratory Animals Center of the First Affiliated Hospital, School of Medicine, Zhejiang University, Zhejiang, People's Republic of China. The mice were caged at $25^{\circ} \mathrm{C}, 12$-hour light/dark cycle, and fed with sterilized standard rat chow and water. All procedures were performed according to the "Guide for the Care and Use of Laboratory Animals" published by the National Institutes of Health (NIH publication 86-23 revised 1985). All animal experiments were approved by the Ethics Committee of the First Affiliated Hospital, School of Medicine, Zhejiang University. 


\section{Isolation and culture of DC from peripheral blood mononuclear cells}

DCs from human peripheral blood mononuclear cells (PBMCs) were obtained by magnetically activated cell sorting (MACS). Briefly, human PBMCs were prepared from blood specimens by Ficoll-Hypaque centrifugation using standard protocol. PBMCs were stained with PE-anti-human Blood Dendritic Cell Antigen 1 (BDCA-1) (Miltenyi Biotec, Cologne, Germany) according to the manufacturer's instruction, and the BDCA-1 ${ }^{+}$ cells were isolated on an MACS column (Miltenyi Biotec). The BDCA- $1^{+}$cells $\left(2 \times 10^{6}\right.$ cells $\left./ \mathrm{mL}\right)$ were immediately suspended in RPMI-1640 medium supplemented with 10\% fetal bovine serum (FBS; Gibco, CA, USA) for cell culture at $37^{\circ} \mathrm{C}$ for 36 hours. Hepatitis B core antigen ( $\mathrm{HBcAg}, \mathrm{HBV}$ core 1-186aa, $2 \mu \mathrm{g} / \mathrm{mL}$; PerSpec, NJ, USA) and HBsAg (HBsAg Adr, $3 \mu \mathrm{g} / \mathrm{mL}$ HyTest, Finland) were added successively into the medium. The medium with $0.3 \%$ bovine serum albumin (BSA; Gibco) was added as control. Then culture supernatant was harvested and the OPN level detected.

\section{PBMC culture with OPN Ab}

PBMCs $\left(2 \times 10^{6}\right.$ cells $\left./ \mathrm{mL}\right)$ from HC were cultured with or without human OPN Ab $(10 \mu \mathrm{g} / \mathrm{mL}$; R\&D systems, Minneapolis, MN; goat IgG was used as control) for 24 hours, and then $\mathrm{HBcAg}$ and HBsAg were added successively. Medium with $0.3 \%$ BSA was added as a control. The supernatant was collected for cytokine detection. Cells were harvested and used to detect the expressions of CD80, CD86, and MHC-II in BDCA-1 cells by flow cytometry.

\section{Preparation of HepG2.2.15 cell supernatant}

HepG2.2.15 cells line is a cell clone from the hepatoblastoma cell line HepG2 that is transfected with a plasmid carrying the HBV gene, and its culture supernatant contains HBV DNA, HBsAg, HBeAg, and Dane particles. ${ }^{30}$ This cell line was cultured in Dulbecco's Modified Eagle's Medium (DMEM, Gibco) supplemented with 10\% FBS and $300 \mu \mathrm{g} / \mathrm{mL}$ G418 (Gibco). Culture supernatants were collected and centrifuged at 4,500 rpm for 10 minutes to remove cell debris. Then HBV DNA level was measured and adjusted to a final concentration of $1 \times 10^{5}$ copies $/ \mathrm{mL}$. Culture supernatants of HepG 2 cells line were prepared in same way.

\section{DC generation from murine bone marrow}

DC was derived from murine bone marrow (BM) as described previously. ${ }^{31}$ Briefly, cell suspensions of murine BM were prepared using conventional procedures. After adherence to plastic, the cells were cultured in DMEM supplemented with $10 \% \mathrm{FBS}, 20 \mathrm{ng} / \mathrm{mL}$ recombined mouse/human granulocytemacrophage colony stimulating factor (GM-CSF), and $10 \mathrm{ng} / \mathrm{mL}$ recombined mouse/human IL-4 (R\&D systems) to generate immature DC. On day $6, \mathrm{HBcAg}(2 \mu \mathrm{g} / \mathrm{mL})$ and HBsAg $(3 \mu \mathrm{g} / \mathrm{mL})$ were added successively. The medium with $0.3 \%$ BSA was added as a control. On day 8 , the supernatant was collected for cytokine detection. Meanwhile, the cells were harvested, and CD11 $\mathrm{c}^{+}$cells were isolated by MACS according to the manufacturer's instructions.

\section{DCs and T-cells coculture in in vitro system}

T-cells were isolated from the wild-type (WT) and $\mathrm{OPN}^{-/-}$ mice spleen by MACS according to the manufacturer's instructions, and then the isolated T-cells were cocultured with $\mathrm{CD} 11 \mathrm{c}^{+}$cells isolated from the cell generation from murine $\mathrm{BM}$ after $\mathrm{HBV}$ antigenic stimulations at a ratio of 10:1. On day 3 , the coculture supernatant was collected for cytokines detection.

\section{Injection of HepG2.2.I5 cell culture supernatant in mice}

To investigate the response to $\mathrm{HBV}$ antigenic stimulation in vivo, two approaches were used. In a first set of experiments, $50 \mu \mathrm{L}$ culture supernatant of HepG2.2.15 cells was directly injected into the mice's liver. ${ }^{23}$ At 24 hours, the mice were sacrificed and the leukocytes in liver were isolated as previously described. ${ }^{23}$ Liver tissues were stained with hematoxylin and eosin. In a second set of experiments, the culture supernatant of HepG2.2.15 cells was hydrodynamically injected into the tail veins in a volume equivalent to $10 \%$ of the mouse body weight, as previously described. ${ }^{32}$ Culture supernatant of HepG2 cells line was injected as control. After 24 hours, the mice were sacrificed and leukocytes in liver were isolated as previously described. ${ }^{23}$ An automated cell counter (Invitrogen, Grand Island, NY, USA) and MXP software (Beckman Coulter, CA, USA) were used to quantify cell numbers.

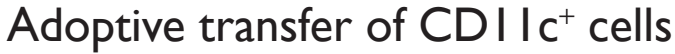

First, leukocytes in liver from the $\mathrm{OPN}^{-/-}$mice and WT mice were isolated, as previously described. ${ }^{23}$ And then the CD $11 \mathrm{c}^{+}$ cells were collected by a MACS column and injected into the liver of $\mathrm{OPN}^{-/-}$mice $\left(2 \times 10^{6}\right.$ cells/mouse $)$ immediately in a volume of $50 \mu \mathrm{L}$ with HepG2.2.15 supernatant. Zero or 24 hours later, the mice were sacrificed and the leukocytes in liver were isolated. 


\section{Stimulating DCs with OPN in vitro}

PBMC $\left(2 \times 10^{6}\right.$ cells $\left./ \mathrm{mL}\right)$ from CHB patients with or without human OPN peptide (vdtydgrgdsvvyglrsks, $1 \mu \mathrm{g} / \mathrm{mL}$ ) were cultured and HBV antigens were added for 24 hours. Cells were harvested and used to detect the expression of surface molecules CD80, CD86, and MHC-II in BDCA- $1^{+}$cells and the IFN- $\gamma$-producing T-cells by flow cytometry.

\section{Flow cytometry}

Expressions of surface molecules on DC were detected by flow cytometry using the following antibodies: PE-antimouse I-Ab/I-Ed (M5/114), PE-anti-mouse B7-1 (1G10), PE-anti-mouse B7-2 (Gl-1), FITC-anti-mouse CD11c (HL3), APC-anti-mouse TCR $\beta$ (H57-597), FITC-anti-human CD80 (L307.4), FITC-anti-human CD86 (2331 (FUN-1)), FITC-antihuman human leukocyte antigen DR (HLA-DR) (G46-6), PE-anti-human BDCA-1 (F10/21A3) and APC-anti-human CD3 (HIT3A) (all from BD Biosciences, San Diego, CA, USA). Intracellular staining was performed using PE-antimouse IFN- $\gamma$ (XMG1.2), PE-anti-mouse IL-4 (11B11), and PE-anti-human IFN- $\gamma$ (4S.B3) (all from BD Biosciences) by using the Cytofix/Cytoperm ${ }^{\mathrm{TM}}$ fixation and permeabilization kit (BD Biosciences). The percentage of positive stained cells was analyzed using MXP software (Beckman Coulter).

\section{ELISA}

OPN (IBL, Gunma, Japan), IL-12, IFN- $\gamma$, TNF- $\alpha$, IL-4, IL-6, and IL-10 concentration were measured using ELISA kits (eBioscience, San Diego, CA, USA), as specified by the manufacturers.

\section{Statistical analysis}

At least three independent experiments were performed, and the representative data are shown unless otherwise indicated. Data were presented as mean \pm SEM. The significance of differences between two groups was determined using Student's $t$-test. $* P<0.05, * * P<0.01$, and $* * * P<0.001$.

\section{Results}

\section{Decreased level of OPN secretion by DCs in $\mathrm{CHB}$ patients}

Some studies have suggested that the function of DCs is considerably weakened in CHB patients. ${ }^{4-7}$ Meanwhile, OPN expression in DCs influences DC function in EAE. ${ }^{26}$ First, we isolated and cultured DCs from PBMCs, and found that DCs could secrete OPN in both $\mathrm{HC}$ and CHB groups (Figure 1). Then we found that the levels of OPN secreted by DCs from CHB patients were significantly lower than those from $\mathrm{HCs}$ (Figure 1, $P<0.001$ ). After $\mathrm{HBcAg}$ stimulation

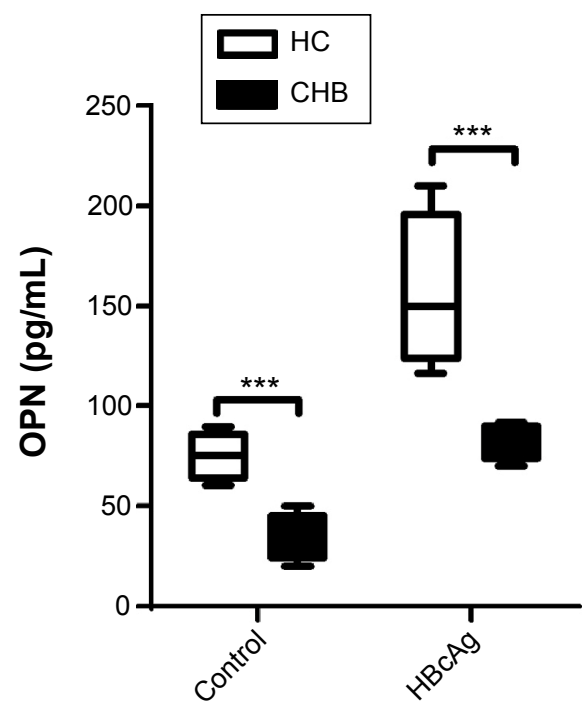

Figure I Decreased level of OPN secretion by DCs in CHB patients. Notes: OPN levels were measured by ELISA in DC culture supernatant with or without $\mathrm{HBcAg}$ stimulation isolated from $\mathrm{PBMC}$ of healthy controls, and the results are presented by box plot; $\mathrm{HC}, \mathrm{n}=20 ; \mathrm{CHB}$ patients, $\mathrm{n}=20$, $* * * \mathrm{P}<0.001$.

Abbreviations: OPN, osteopontin; DCs, dendritic cells; $\mathrm{CHB}$, chronic hepatitis $\mathrm{B}$; $\mathrm{HBcAg}$, hepatitis $\mathrm{B}$ core antigen; PBMC, peripheral blood mononuclear cells; $\mathrm{HC}$, healthy controls; ELISA, enzyme-linked immunosorbent assay.

on DCs, the levels of OPN secreted by DCs increased in both groups $(P<0.01)$ but remained lower in CHB patients vs HCs (Figure $1, P<0.001$ ).

\section{OPN Ab inhibited costimulatory molecular expression and IL-I 2 production of DC after HBV antigenic} stimulation in human PBMC

DCs from CHB patients secreted a decreased level of OPN, so we examined whether OPN blockage induced by OPN Ab affected the phenotypical maturity of DCs. We found that BDCA- $1^{+}$cells (DCs) expressed higher levels of maturation markers CD80 and CD86 after HBcAg and HBsAg stimulations than those in the control group (Figure 2A). Importantly, the in vitro anti-OPN Ab treatment significantly reduced the expression of CD 80 and CD86 on BDCA- $1^{+}$cells after HBV antigenic stimulations (Figure $2 \mathrm{~A}$ and $\mathrm{B}$; both $P<0.05$ ). We also detected HLA-DR expression on the surface of DCs and found a downward trend after OPN Ab administration. DCs mainly produced IL-12 after maturation, which plays a vital role in the process of T-cell activation. We next detected levels of IL-12 with OPN Ab administration, and found that the secretion of IL-12 was suppressed after HBV antigenic stimulation in the supernatant of PBMCs with blocked OPN (Figure 2C, both $P<0.05$ ).

DCs can dispose of antigens and present antigens to T-cells after antigenic stimulation, thereby inducing the activation of T-cells and triggering adaptive immune response. 

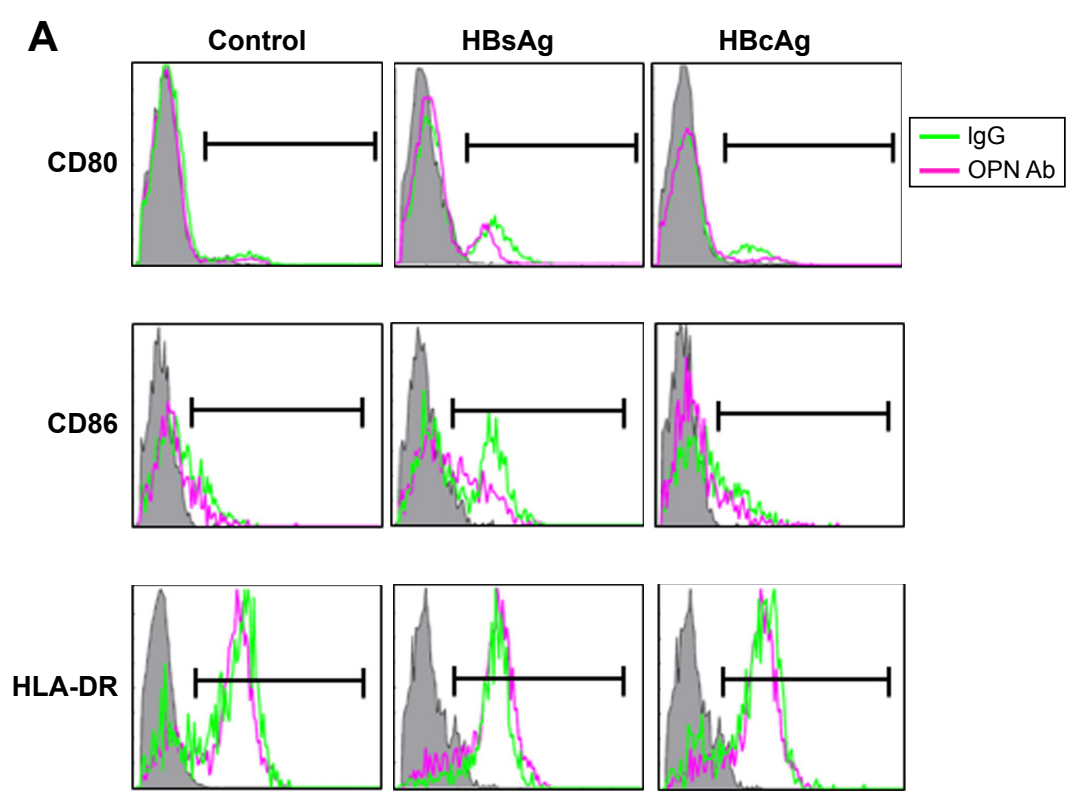

B
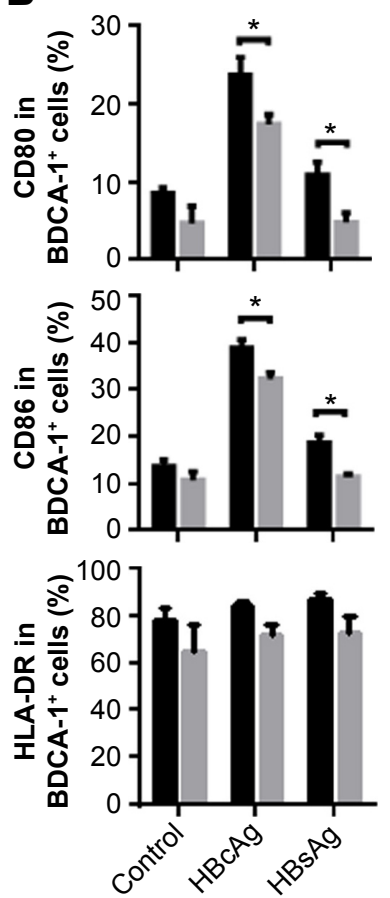

C

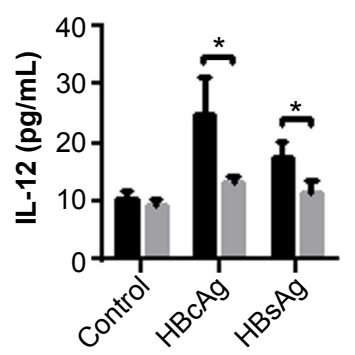

D

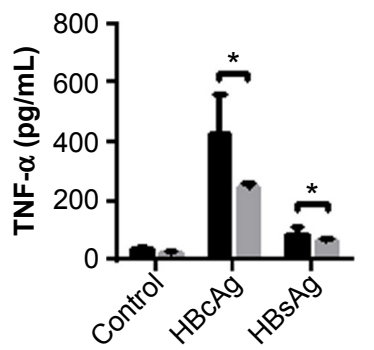

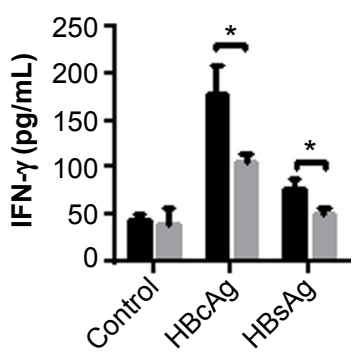

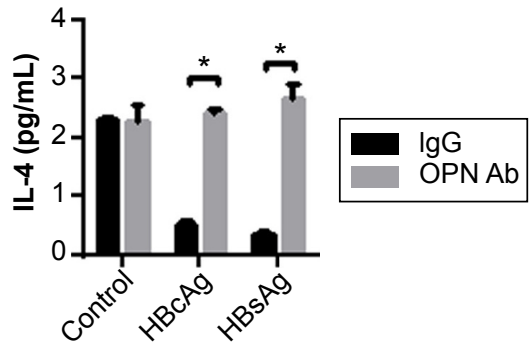

Figure 2 Blockage of OPN suppressed DC maturation and cytokine production after hepatitis B virus (HBV) antigenic stimulations in human PBMC.

Notes: After administering OPN neutralizing antibody in vitro, the histograms (A) and expressions (B) of CD80, CD86, and HLA-DR in BDCA-I+ cells after HBV antigenic stimulations in human PBMCs are presented. Overlay plots are representative and show isotype control (shadow) and the expressions of the indicated molecules on DCs in the absence (green line) or presence (red line) of neutralizing antibody in each group. Levels of IL-I2 (C), TNF- $\alpha$, IFN- $\gamma$, and IL-4 (D) in human PBMC supernatant were measured after administering the OPN-neutralizing antibody in vitro as well as $\mathrm{HBcAg}$ and $\mathrm{HBs} \mathrm{Ag}$ stimulations. $* \mathrm{P}<0.05$.

Abbreviations: OPN, osteopontin; DCs, dendritic cells; HBV, hepatitis B virus; $\mathrm{HBcAg}$, hepatitis B core antigen; HBsAg, hepatitis B surface antigen; PBMC, peripheral blood mononuclear cells; IL, interleukin; TNF, tumor necrosis factor; IFN, interferon; Ab, antibody; IgG, Immunoglobulin gamma; HLA-DR, human leukocyte antigen-DR; BDCA-I, blood dendritic cell antigen I.

Thus we determined the levels of Th1 and Th2 cytokines in the supernatant of PBMCs culture. We found that the levels of IFN- $\gamma$ and TNF- $\alpha$ were decreased (both $P<0.05$ ) while IL-4 levels were significantly increased $(P<0.05)$ on OPN blockage after $\mathrm{HBcAg}$ and $\mathrm{HBsAg}$ stimulation (Figure 2D). These data suggested that OPN blockage suppressed DC maturation and IL-12 production and decreased Th1 cytokines but increased Th2 cytokines in human PBMCs following HBV antigenic stimulations.

\section{OPN deficiency impaired DC maturation and IL- 12 production in mice after HBV antigenic stimulation}

To address the role of $\mathrm{OPN}$ in the maturation and functioning of DCs, we next compared the BM-derived DCs (BMDCs) from $\mathrm{OPN}^{-/-}$mice and WT mice. We determined the expression of
CD80, CD86, and MHC-II on BMDCs from WT mice and $\mathrm{OPN}^{-/-}$mice. First, there were no significant differences in the expression of CD80, CD86, and MHC-II in BMDCs between WT mice and $\mathrm{OPN}^{-/}$mice without stimulation (control) (Figure 3A-D). However, these molecular expressions markedly decreased in $\mathrm{OPN}^{-/}$mice vs WT mice after $\mathrm{HBV}$ antigenic stimulations (Figure 3A-D). Similar results were obtained from the hepatic DCs of $\mathrm{OPN}^{-/-}$mice and WT mice (data not shown). Thus, these data suggested that the absence of OPN induced a low expression of surface molecules on DCs following stimulation with HBV antigens in mice.

To further verify whether the functioning of DCs was influenced by OPN after HBV antigen stimulation, we analyzed the cytokines secreted by BMDCs of WT mice and $\mathrm{OPN}^{-/-}$mice. We found that the level of IL-12 secreted by $\mathrm{OPN}^{-/-}$DCs decreased when stimulated with $\mathrm{HBcAg}$ and 

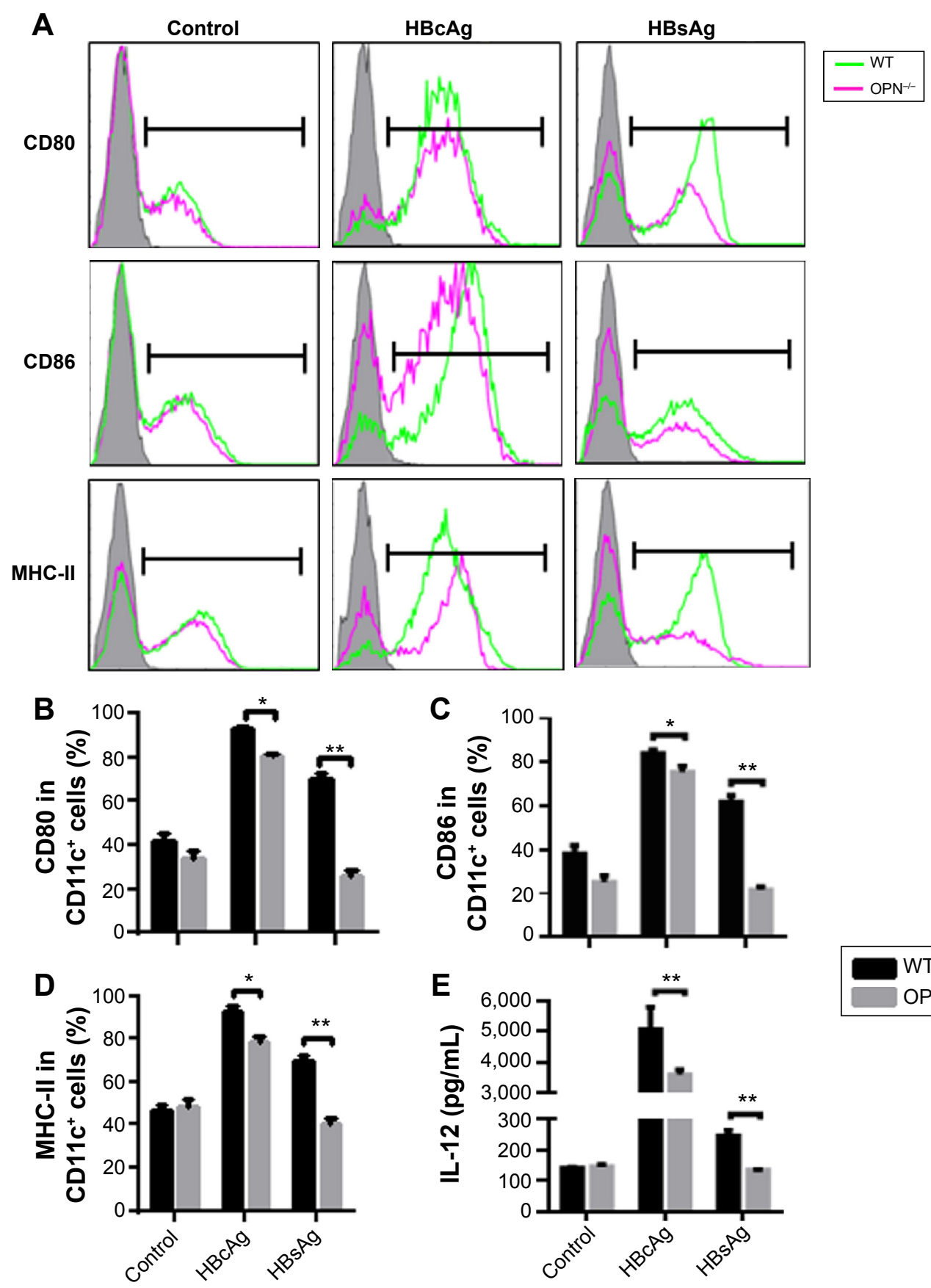

Figure 3 OPN deficiency impaired DCs maturation and function after HBV antigenic stimulation in vitro.

Notes: DCs derived from BM of the WT and OPN ${ }^{-1-}$ mice were stimulated by HBV antigens. The histograms (A) and percentages (B-D) of CD80, CD86, and MHC-II molecules on the DC surface were detected by flow cytometry. Overlay plots are representative and show isotype control (shadow) and the expressions of the indicated molecules on DCs from WT mice (green line) or OPN ${ }^{-1-}$ mice (red line) in each group. (E) Levels of IL-I 2 in the BMDC culture supernatants following different stimulations were measured by ELISA. $* P<0.05 ; * * P<0.01$.

Abbreviations: OPN, osteopontin; DCs, dendritic cells; HBV, hepatitis B virus; BM, bone marrow; WT, wild-type; $H B c A g$, hepatitis B core antigen; $H B s A g$, surface antigen of the hepatitis B virus; MHC, major histocompatibility complex; IL, interleukin; BMDC, bone marrow-derived dendritic cell; ELISA, enzyme-linked immunosorbent assay.

HBsAg compared with that in WT DCs (Figure 3E, both $P<0.01)$. We also found that hepatic DCs similarly secreted IL-12 upon stimulation (data not shown). These results further indicated that OPN deficiency could induce a low expression of surface molecules on DCs and decrease IL-12 secretion by DCs when stimulated with HBV antigens in vitro.

\section{OPN deficiency impaired induction} of polarized ThI responses to HBV antigens through DCs

To further investigate whether OPN plays a crucial role in regulatory effects of DCs on Th1/Th2 cytokines balance, we adopted an in vitro system in which DCs and T-cells were 
cocultured. T-cells were isolated from the spleen of WT and $\mathrm{OPN}^{--}$mice by MACS and cocultured with BMDCstimulated HBV antigens, and the cytokine levels (TNF- $\alpha$, IFN- $\gamma$, IL-4 and IL-10) were determined.

We found that the levels of TNF- $\alpha$ and IFN- $\gamma$ were significantly decreased while the levels of IL-4 and IL-10 were significantly elevated in the cocultured supernatants of $\mathrm{OPN}^{-/-}$DCs and WT T-cells compared with the cocultured supernatant of WT DCs and WT T-cells (Figure 4A-D). Similar results were observed in the cocultured supernatant of $\mathrm{OPN}^{-/-} \mathrm{DCs}$ and $\mathrm{OPN}^{-/} \mathrm{T}$-cells compared with the cocultured supernatant of WT DCs and $\mathrm{OPN}^{-/-} \mathrm{T}$-cells (Figure 4A-D). Thus, these results show that the lack of OPN in DCs results in impaired induction of polarized Th1 responses and enhanced induction of polarized Th2 responses in the process of T-cell response induced by DCs after HBV antigenic stimulations. In addition, we found no significant difference in cytokines levels in the supernatant of WT DCs cocultured with WT T-cells or OPN ${ }^{-/}$T-cells, and $\mathrm{OPN}^{-/-}$DCs co-cultured with WT T-cells or $\mathrm{OPN}^{-/-}$ T-cells (Figure S1). These data show that the lack of OPN in T-cells was dispensable in regulatory effects of DCs on Th1/Th2 cytokines balance.

A

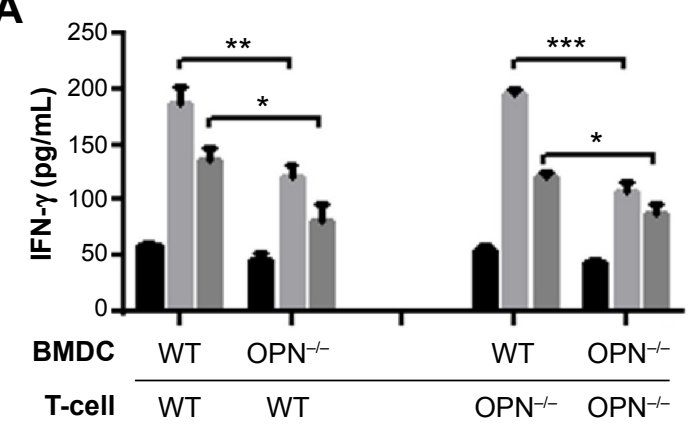

C

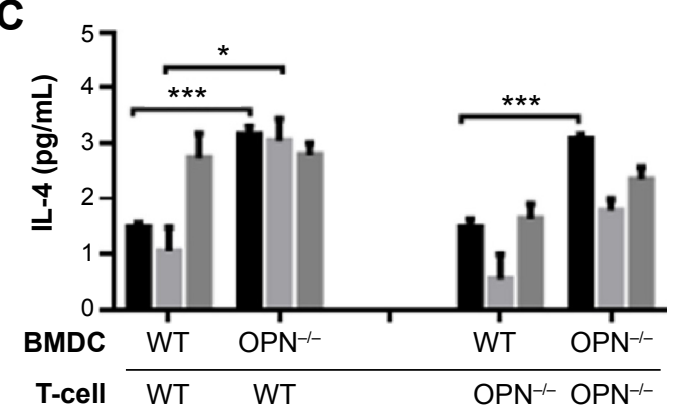

OPN produced by DCs played an important role in response to HBV antigenic stimulation in vivo

To further address the role of OPN on the immune response to HBV antigens, we compared liver inflammation after HepG2.2.15 supernatant injection into the liver of $\mathrm{OPN}^{-/-}$and WT mice. We found that the number of liver infiltrating cells of $\mathrm{OPN}^{-/}$mice was significantly reduced compared with WT mice, as seen by histological examination (Figure 5A) and cell counts (Figure 5B, $P<0.05$ ). To explore the underlying mechanisms of OPN involved in liver inflammation, we examined DCs in the liver. We found that the percentages of DCs were similar in liver from $\mathrm{OPN}^{-/-}$mice and WT mice after HepG2.2.15 supernatant injection (Figure S2). However, the expression of CD80, CD86, and MHC-II were decreased on DCs from the $\mathrm{OPN}^{-/}$mice vs WT mice (Figure 5C). Meanwhile, the number of $\mathrm{TCR}^{+} \mathrm{T}$-cells infiltrating into the liver in $\mathrm{OPN}^{-/}$mice was significantly lower than that in WT mice (Figure 5D, $P<0.05$ ). Moreover, the number of IFN- $\gamma$-producing T-cells was markedly decreased in the $\mathrm{OPN}^{-/}$mice vs WT mice $(P<0.01)$, while the number of IL-4-producing T-cells showed no significant difference after HBV antigenic stimulation (Figure 5E).

B

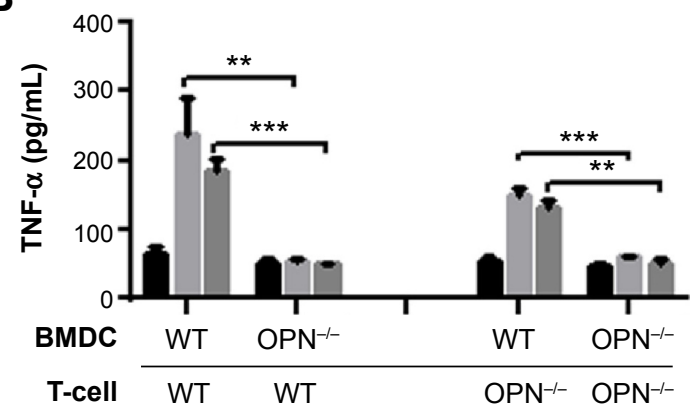

D

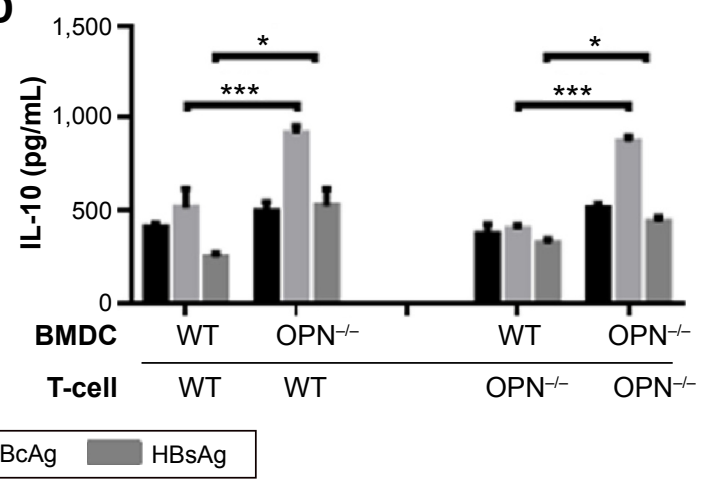

Figure 4 OPN deficiency impaired the induction of polarized ThI responses to HBV antigens through DCs.

Notes: T-cells were isolated from the WT and OPN ${ }^{-1-}$ mice spleen by MACS and cocultured with CDII $\mathrm{c}^{+}$cells isolated from the cell derived from murine BM of WT mice and $\mathrm{OPN}^{-1-}$ mice after $\mathrm{HBV}$ antigenic stimulations at a ratio of I0:I, respectively, and then cytokines levels in the coculture supernatants were detected by ELISA. The levels of IFN- $\gamma(\mathbf{A})$, TNF- $\alpha(\mathbf{B})$, IL-4 (C) and IL-I0 (D) in the coculture supernatants are compared. $* P<0.05 ; * * P<0.0$ I. $* * * P<0.00$ I.

Abbreviations: OPN, osteopontin; DCs, dendritic cells; HBV, hepatitis B virus; BM, bone marrow; WT, wild-type; MACS, magnetically activated cell sorting; HBcAg, hepatitis B core antigen; $\mathrm{HBsAg}$, surface antigen of the hepatitis B virus; IL, interleukin; TNF, tumor necrosis factor; IFN, interferon; BMDC, bone marrow-derived dendritic cell; ELISA, enzyme-linked immunosorbent assay. 

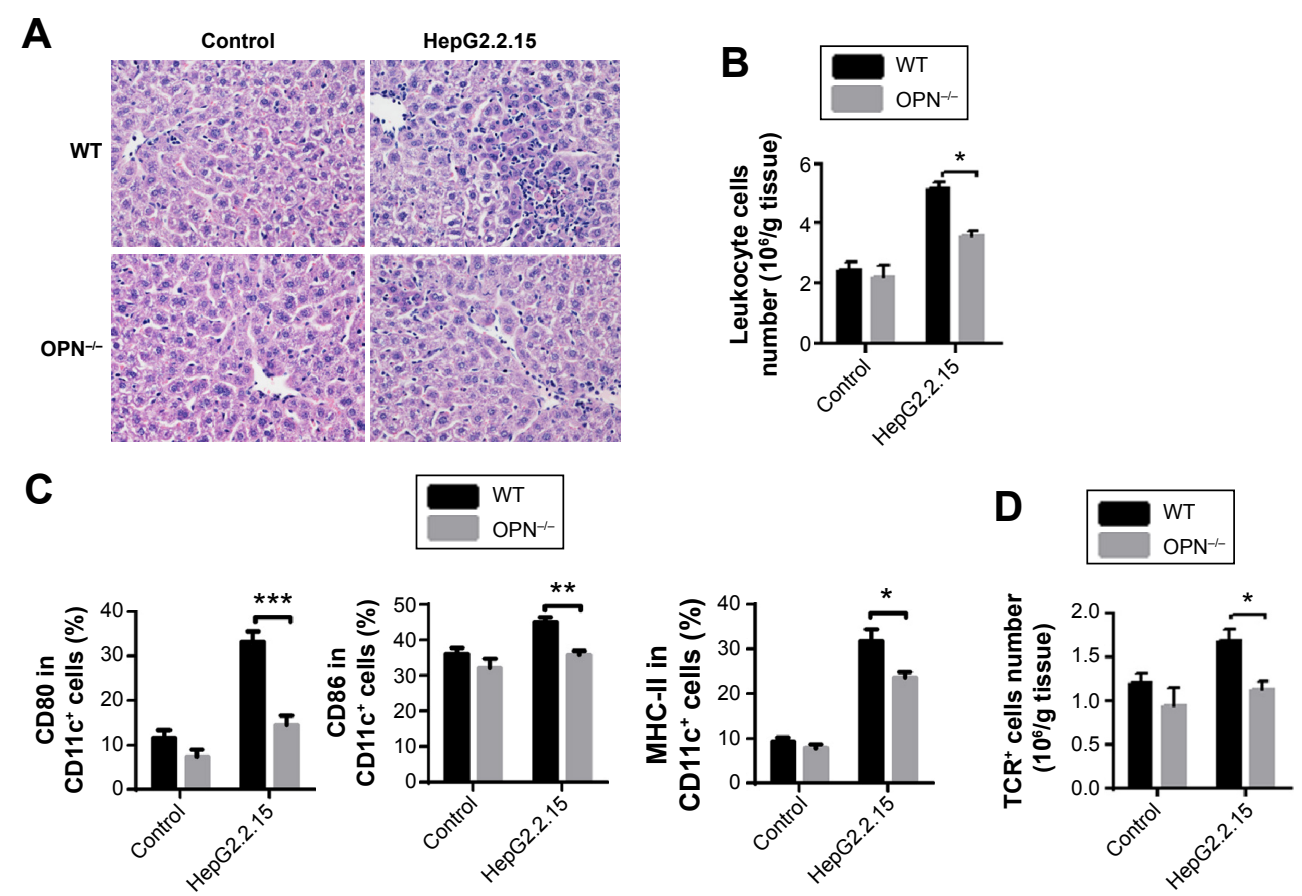

E
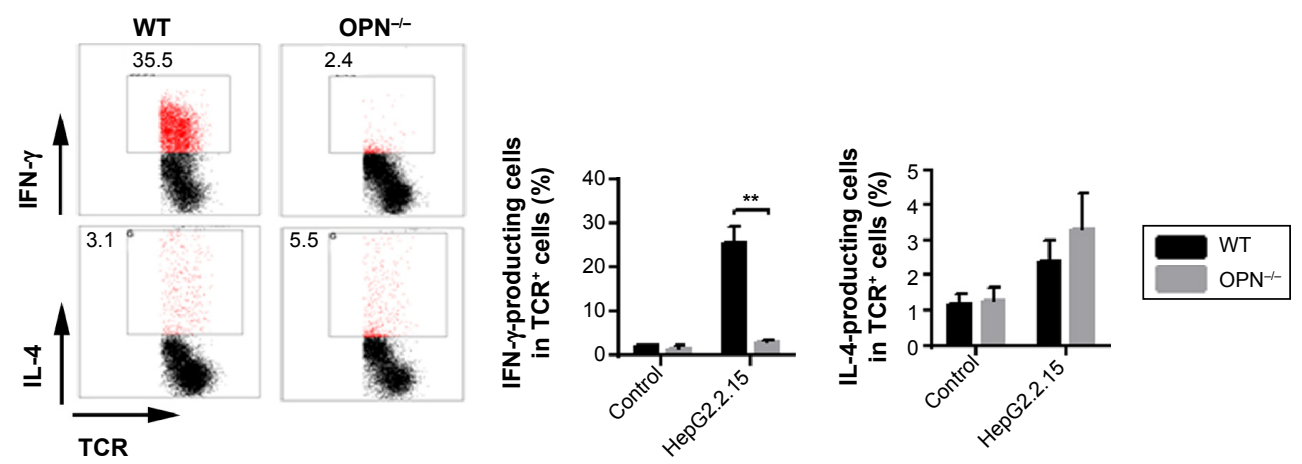

$\mathbf{F}$

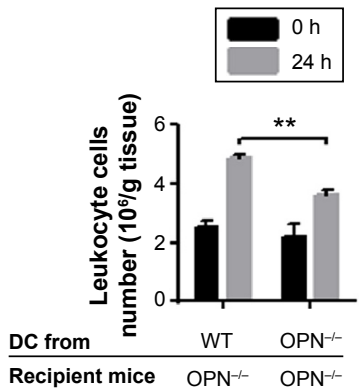

G

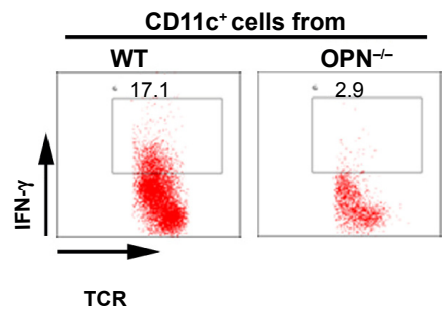

Figure 5 OPN produced by DCs plays an important role in response to HBV antigenic stimulation in vivo.

Notes: At 24 hours after HepG2.2.15 cells supernatant direct injection into liver from the WT mice and OPN ${ }^{-1-}$ mice $(\mathbf{A})$ liver histology was assessed. Original magnification, 400×. (B) Leukocyte number and (C) expressions of CD80, CD86, and MHC-II molecules on DCs in liver from the WT mice and OPN ${ }^{-1-}$ mice were measured. (D) Number of $\mathrm{TCR}^{+}$cells per gram of liver tissue were detected by an automated cell counter and flow cytometry. (E) Number of IFN- $\gamma$-producing T-cells and IL-4-producing T-cells were detected. HepG2 supernatant injection was used as control. $\mathrm{n}=5$ per group. Adoptive transfer of CDII $\mathrm{c}^{+}$cells from the WT and OPN ${ }^{-1-}$ mice as well as HepG2.2.I5 supernatant direct injection into mice liver were performed. Then $(\mathbf{F})$ the number of leukocyte per gram of liver tissue was counted in the OPN ${ }^{-1-}$ mice at 0 and 24 hours; $\mathrm{n}=5$ per group. (G) IFN- $\gamma$-producing cells in T-cells in liver from the $\mathrm{OPN}^{-1-}$ mice were analyzed. $\mathrm{n}=5$ per group. $* \mathrm{P}<0.05$; $* * P<0.0 \mathrm{I} ; * * * P<0.00 \mathrm{I}$.

Abbreviations: OPN, osteopontin; DCs, dendritic cells; HBV, hepatitis B virus; WT, wild-type; MHC, major histocompatibility complex; IL, interleukin; IFN, interferon; TCR, T-cell receptor; h, hour.

Similarly, we also found significantly decreased leukocyte infiltration into the liver (Figure S3A, $P<0.01$ ) from the $\mathrm{OPN}^{-/-}$mice vs WT mice, as seen by hydrodynamic injection of HepG2.2.15 cells culture supernatant. In addition, the number of IFN- $\gamma$-producing T-cells was decreased in the $\mathrm{OPN}^{-/}$mice vs WT mice (Figure S3C, $P<0.01$ ), while IL-4-producing T-cells presented no significant difference (Figure S3C). 
To provide further evidence of the contribution of DCs and OPN to the immune response to HBV antigens, we tested whether adoptive transfer of DCs from WT mice could render $\mathrm{OPN}^{-/-}$mice susceptible to $\mathrm{HBV}$ antigens. Intrahepatic injection of C57BL/6-derived (isolated) DCs $\left(\mathrm{CD} 11 \mathrm{c}^{+}\right)$cells along with HepG2.2.15 supernatant presented more obvious inflammatory cell infiltration in $\mathrm{OPN}^{-/-}$mice than the injection of DCs $\left(\mathrm{CD} 11 \mathrm{c}^{+}\right)$derived (isolated) (Figure $5 \mathrm{~F}, P<0.01$ ), though there was an upward trend after adoptive transfer DCs from $\mathrm{OPN}^{-/}$ mice. We further analyzed the influence of DCs on IFN$\gamma$-producing T-cells, and noted that the number of such cells was markedly increased in the $\mathrm{OPN}^{-/}$mice after adoptive transfer of DCs from the WT mice vs $\mathrm{OPN}^{-/-}$mice ( $17.1 \%$ vs $2.9 \%$, Figure $5 \mathrm{G})$. These results suggested that OPN deficiency induced a decrease of inflammatory cell infiltration in the liver after HBV antigenic stimulation in vivo. And DCs from WT, rather than $\mathrm{OPN}^{-/-}$mice, restored $\mathrm{HBV}$-induced response in the $\mathrm{OPN}^{-/-}$mice, which indicated that OPN produced by DCs played an important role in response to $\mathrm{HBV}$ antigenic stimulation.

\section{OPN administration significantly promoted the functioning of DCs from $\mathrm{CHB}$ patients upon HBV antigenic stimulation}

Although several lines of evidences have demonstrated that the $\mathrm{HBV}$-specific $\mathrm{DC}$ vaccine shows great promise for $\mathrm{CHB}$ patients ${ }^{20-22}$ the generation of a more functional $\mathrm{DC}$ vaccine for the efficient therapy of $\mathrm{CHB}$ remains a challenge. ${ }^{22}$ Therefore, we tested whether exogenous OPN enhanced the function of DCs from CHB patients in vitro. Administration of exogenous OPN significantly increased the expression of CD80 and CD86 on BDCA- $1^{+}$cells from the peripheral blood of $\mathrm{CHB}$ patients following $\mathrm{HBcAg}$ stimulations (Figure 6A and $\mathrm{B}$ ), while the expression of HLA-DR on BDCA- $1^{+}$ cells showed no obvious difference after OPN addition (Figure 6C). Moreover, we further determined that the percentages of IFN- $\gamma$-producing T-cells were markedly increased after $\mathrm{HBcAg}$ stimulation combined with OPN compared to HBcAg stimulation alone (17.7\% vs $4.5 \%$, Figure 6D). These results suggested that OPN administration could significantly promote the functioning of DCs from CHB patients after
A
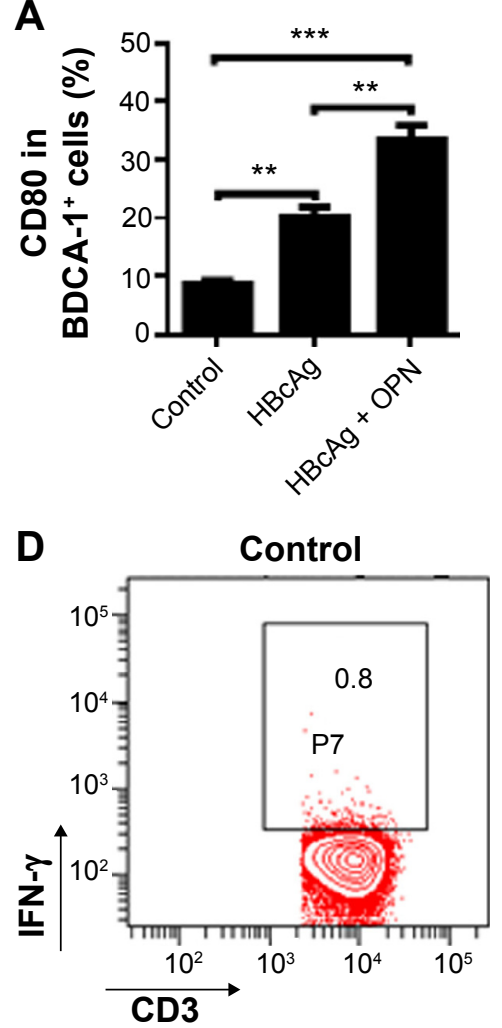

B
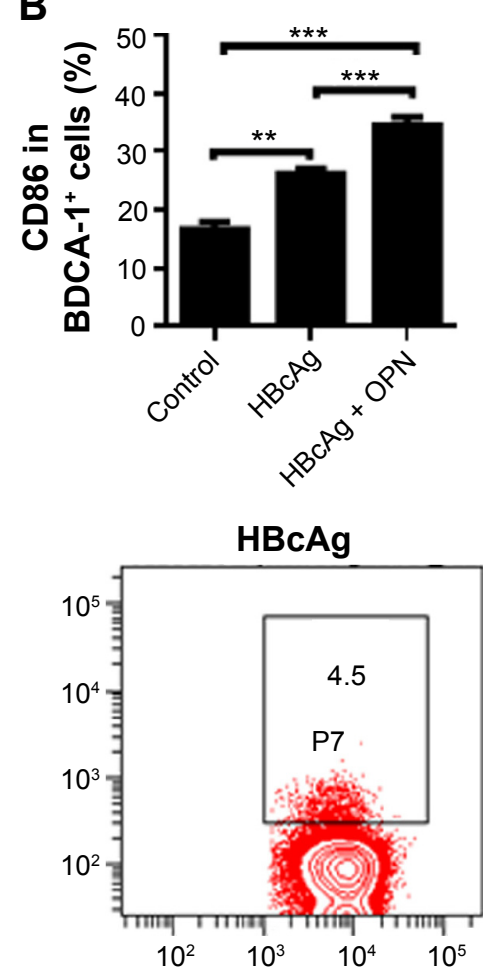
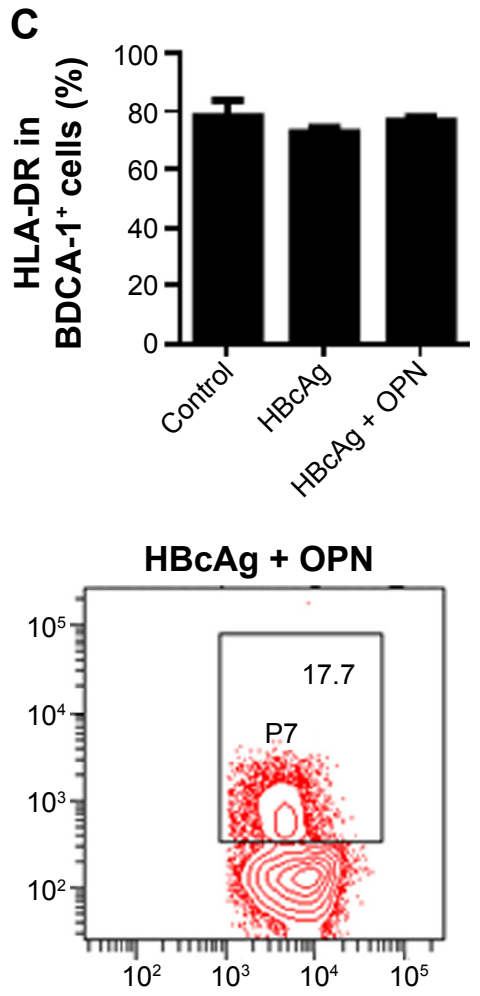

Figure 6 OPN administration significantly promoted the maturation of DCs from CHB patients after $\mathrm{HBCAg}$ stimulation.

Notes: The expressions of CD80 (A), CD86 (B), and HLA-DR (C) in BDCA- I+ cells from the peripheral blood of CHB patients following HBcAg stimulation with or without exogenous OPN administration were measured by flow cytometry. $\mathrm{CHB}$ patients, $\mathrm{n}=20$. ${ }^{*} * \mathrm{P}<0.0 \mathrm{I}$, $* * * P<0.00 \mathrm{I}$. (D) The percentages of IFN- $\gamma$-producing cell in $\mathrm{CD} 3^{+} \mathrm{T}$-cells from the peripheral blood of $\mathrm{CHB}$ patients following $\mathrm{HBcAg}$ stimulation with or without exogenous OPN administration were measured by flow cytometry.

Abbreviations: OPN, osteopontin; DCs, dendritic cells; CHB, chronic hepatitis B; HBV, hepatitis B virus; HBcAg, hepatitis B core antigen; IFN, interferon; HLA-DR, human leukocyte antigen-DR; BDCA-I, Blood Dendritic Cell Antigen I. 
HBV antigenic stimulation, which might have the potential to enhance the effect of HBV-specific DC vaccine.

\section{Discussion}

DCs play an important role in HBV infection and influence the activation of T-cells via antigen presentation and cytokine secretion by mature DCs. ${ }^{8,19}$ A study showed that OPN promotes the migration and activation of DCs in the epidermis, ${ }^{33}$ and another study showed that OPN regulates IFNAR on DCs in EAE. ${ }^{26}$ However, it remains unclear whether OPN affects DCs' functioning during the physiopathological process of HBV infection. Here we found that OPN production of DCs from CHB patients was significantly lower than that from healthy volunteers. The absence of OPN impaired DC maturation and functioning upon stimulation with $\mathrm{HBV}$ antigen. Defective DC function led to reduced activation of Th1 in response to $\mathrm{HBV}$ antigens. In addition, OPN deficiency in DCs reduced the $\mathrm{HBV}$ antigen-induced inflammatory response and IFN- $\gamma$ production of T-cells in the liver of mice. Importantly, OPN administration significantly promoted the functioning of DCs from $\mathrm{CHB}$ patients in vitro. These findings suggested that OPN could improve the maturation and functioning of DCs in the immune response to HBV antigens, and might be useful to further improve the effect of DC vaccine.

Previous studies have suggested that OPN expression in T-cells is essential for the efficient skewing of $\mathrm{CD}^{+}$ T-cells toward the Th1 cells pathway. ${ }^{34,35}$ We previously demonstrated that resident intrahepatic invariant natural killer $\mathrm{T}$ (iNKT) cells clearly expressed OPN and that OPN was involved in the activation of iNKT cells in ConA-induced hepatitis. ${ }^{36}$ And in HBV infection, functional impairment of DCs may mediate the suppression of viral-specific T-cell immune responses, resulting in viral persistence. ${ }^{4-7}$ We noted that DCs secreted OPN in healthy volunteers and that the production of OPN by DCs in CHB patients was impaired. Thus, we attempted to clarify whether OPN affected the maturation and secretory function of DCs during the process of $\mathrm{HBV}$ infection, thereby studying the regulatory function of OPN on DCs in this process.

As costimulatory molecules and maturation markers, ${ }^{16}$ CD80 and CD86 can assist MHC-II to present antigens and activate T-cells, thereby playing a critical role in defending pathogen infection. ${ }^{17,18} \mathrm{We}$ found that the costimulatory molecules CD80 and CD86 on human DCs were decreased after HBcAg stimulation when OPN was blocked. The decreased expressions of CD80 and CD86 on DCs were not beneficial for antigen presentation of $\mathrm{HBV} .{ }^{37}$ In addition, IL-12 is mainly produced by mature DCs, which play a vital role in the process of T-cell activation. Our results showed that a lack of OPN suppressed the secretion of IL-12 after HBV antigenic stimulation. Th1 cytokines play an important role in the immunopathology of $\mathrm{CHB}$ and the elimination of HBV infection. ${ }^{38}$ We found that a lack of OPN reduced the levels of TNF- $\alpha$ and IFN- $\gamma$ after HBV antigenic stimulation. These data indicated that OPN could promote DC function and enhance Th1 cytokines after stimulation with HBV antigens.

HBV infection is thought to involve an imbalance of Th1/ Th2 cells. ${ }^{39}$ Total viral load is negatively correlated with Th1 cytokines but positively correlated with IL-4 and IL-10. ${ }^{39,40}$ To further verify that OPN influences T-cell response to HBV antigens via antigen presentation of DCs, the $\mathrm{OPN}^{-/-} \mathrm{DCs}$ and WT DCs stimulated by HBV antigens were harvested and cocultured with $\mathrm{OPN}^{-/-} \mathrm{T}$-cells and WT T-cells, respectively. We found that the OPN deficiency of DCs decreased Th1 cytokines and increased Th2 cytokines after stimulation with HBV antigens and impaired the induction of polarized Th1 responses. However, the OPN deficiency in T-cells was not crucial in polarized Th1 responses.

To provide further evidence of OPN contribution to immune response to $\mathrm{HBV}$ antigens, we compared liver inflammation after $\mathrm{HBV}$ antigenic stimulation in the $\mathrm{OPN}^{-/-}$ and WT mice by intrahepatic injection of Hep2.2.15 culture supernatant. In the $\mathrm{OPN}^{-/}$mice, inflammatory cell infiltration in liver was significantly reduced compared to WT mice, and adoptive transfer of DCs from the WT rather than $\mathrm{OPN}^{-/-}$mice restored the inflammatory response to $\mathrm{HBV}$ antigens in the $\mathrm{OPN}^{-/}$mice, though there was an upward trend after adoptive transfer of DCs from $\mathrm{OPN}^{-/}$mice. The upward trend was due to the increase in the number of DCs after DC adoptive transfer. Through DCs from $\mathrm{OPN}^{-/}$mice were impaired, they also possessed some functions, such as secreting low levels of IL-12. The inflammation response could be enhanced 24 hours after adoptive transfer of DCs from $\mathrm{OPN}^{-/}$mice via the improved DC functions induced by the increase of DCs number. Hydrodynamic injections of plasmid-containing HBV antigens were used to study the in vivo immune response to $\mathrm{HBV},{ }^{32}$ so we next performed hydrodynamic injection of Hep2.2.15 culture supernatant to observe the effect of OPN on the immune response to $\mathrm{HBV}$, and found similar results. These data suggested that OPN deficiency in DCs significantly reduced the inflammatory response against HBV antigens in the liver. Persistent HBV infection is thought to involve an impaired Th1 immune response. ${ }^{39,40}$ Many studies have shown that the impaired DC function may be an important mechanism 
by which HBV can escape from the immune response and induce persistent infection in CHB patients. ${ }^{8,19,41}$ Our data suggested that OPN deficiency in DCs impaired the functioning of DCs, resulting in an inefficient immune response to $\mathrm{HBV}$ in vivo.

In addition, patients with better DC function have better response to HBV vaccine therapy. ${ }^{41}$ Hence, the activation of DCs is a key to anti-HBV therapy. In our study, we found that a lack of OPN induced immature and deficient secretory functions in DCs and inhibited the activation of Th1 induced by DCs after stimulation with HBV antigens. Recent studies have also demonstrated that DC vaccine can be used to treat CHB patients. ${ }^{20-22,42,43}$ However, the efficacy of the DC vaccine was unsatisfactory. In this study, the addition of OPN to the DC culture induced the upregulated expressions of CD80 and CD86 on the surface of DCs as well as IL-12 production in vitro. Moreover, OPN increased the IFN- $\gamma$ production of T-cells upon HBcAg stimulation. These data further suggested that OPN improved the functioning and maturity of DCs during the process of HBV infection, which was beneficial for further improvements of DC vaccine.

\section{Conclusion}

In conclusion, OPN production of DCs from $\mathrm{CHB}$ patients was significantly lower than those from healthy volunteers. The absence of OPN impaired DC function upon stimulation with HBV antigens. Defective DC function led to reduced activation of Th1 in response to $\mathrm{HBV}$ antigens. In addition, OPN deficiency in DCs reduced the HBV antigen-induced inflammatory response in the liver of mice. Importantly, OPN administration significantly promoted the function of DCs from CHB patients in vitro. These findings suggested that OPN could improve the maturation and functioning of DCs in the immune response to HBV antigens, and might be useful to further improve the effect of DC vaccine.

\section{Acknowledgments}

This work was supported by the National Natural Science Foundation of China (81271810), the 12-5 state S\&T Projects for infectious diseases (2012ZX10002-007), the National Basic Research Program of China (2013CB531405), and the Doctoral Fund of Ministry of Education of China (20120101110009).

\section{Author contributions}

GYC and HYD conceived, designed, and performed most of the experiments with significant contributions from JNC,
JQH, CL, WL, TU and LJL; GYC, YFW, and JNC analyzed the data; and GYC and HYD wrote the paper. All authors contributed toward data analysis, drafting and revising the paper and agree to be accountable for all aspects of the work.

\section{Disclosure}

The authors report no conflict of interest in this work.

\section{References}

1. WHO.int [World Health Organization]. Hepatitis B; 2015 [updated March, 2015]. Available from: http://www.who.int/mediacentre/factsheets/fs204/en/. Accessed March 21, 2015.

2. Lv G, Ying L, Ma WJ, et al. Dynamic analysis of CD127 expression on memory CD8 T cells from patients with chronic hepatitis B during telbivudine treatment. Virol J. 2010;7:207.

3. Rehermann B, Nascimbeni M. Immunology of hepatitis B virus and hepatitis C virus infection. Nat Rev Immunol. 2005;5:215-229.

4. Chen L, Zhang Z, Chen W, et al. B7-H1 up-regulation on myeloid dendritic cells significantly suppresses $\mathrm{T}$ cell immune function in patients with chronic hepatitis B. J Immunol. 2007;178:6634-6641.

5. Zhang Z, Zou ZS, Fu JL, et al. Severe dendritic cell perturbation is actively involved in the pathogenesis of acute-on-chronic hepatitis B liver failure. J Hepatol. 2008;49:396-406.

6. van der Molen RG, Sprengers D, Binda RS, et al. Functional impairment of myeloid and plasmacytoid dendritic cells of patients with chronic hepatitis B. Hepatology. 2004;40:738-746.

7. Löhr HF, Pingel S, Böcher WO, et al. Reduced virus specific T helper cell induction by autologous dendritic cells in patients with chronic hepatitis B - restoration by exogenous interleukin-12. Clin Exp Immunol. 2002;130:107-114.

8. Cui GY, Diao HY. Recognition of HBV antigens and HBV DNA by dendritic cells. Hepatobiliary Pancreat Dis Int. 2010;9:584-592.

9. Kalinski P, Hilkens CM, Wierenga EA, Kapsenberg ML. T-cell priming by type- 1 and type- 2 polarized dendritic cells: the concept of a third signal. Immunol Today. 1999;20:561-567.

10. Yamane H, Paul WE. Cytokines of the gamma(c) family control CD4+ T cell differentiation and function. Nat Immunol. 2012;13:1037-1044.

11. Murphy KM, Reiner SL. The lineage decisions of helper T cells. Nat Rev Immunol. 2002;2:933-944.

12. Lanzavecchia A, Sallusto F. Regulation of T cell immunity by dendritic cells. Cell. 2001;106:263-266.

13. Nouri-Shirazi M, Kahlden C, Nishino P, Guinet E. Nicotine exposure alters the mRNA expression of Notch ligands in dendritic cells and their response to Th1-/Th2-promoting stimuli. Scand J Immunol. 2015;81: 110-120.

14. Li L, Lee HH, Bell JJ, et al. IL-4 utilizes an alternative receptor to drive apoptosis of Th1 cells and skews neonatal immunity toward Th2. Immunity. 2004;20:429-440.

15. Zhu J, Jankovic D, Oler AJ, et al. The transcription factor T-bet is induced by multiple pathways and prevents an endogenous Th2 cell program during Th1 cell responses. Immunity. 2012;37:660-673.

16. Zhang S, Saha B, Kodys K, Szabo G. IFN-gamma production by human natural killer cells in response to $\mathrm{HCV}$-infected hepatoma cells is dependent on accessory cells. J Hepatol. 2013;59:442-449.

17. Jimenez F, Quinones MP, Martinez HG, et al. CCR2 plays a critical role in dendritic cell maturation: possible role of CCL2 and NF-kappa B. J Immunol. 2010;184:5571-5581.

18. Marim FM, Silveira TN, Lima DS Jr, Zamboni DS. A method for generation of bone marrow-derived macrophages from cryopreserved mouse bone marrow cells. PLoS One. 2010;5:e15263.

19. He D, Yan G, Wang Y. Serum levels of interleukin-12 in various clinical states with hepatitis B virus infection. Cell Immunol. 2012;272: $162-165$. 
20. Chen M, Li YG, Zhang DZ, et al. Therapeutic effect of autologous dendritic cell vaccine on patients with chronic hepatitis B: a clinical study. World J Gastroenterol. 2005;11:1806-1808.

21. Akbar SM, Furukawa S, Horiike N, Onji M. Vaccine therapy for hepatitis B virus carrier. Curr Drug Targets Infect Disord. 2004;4:93-101.

22. Luo J, Li J, Chen RL, et al. Autologus dendritic cell vaccine for chronic hepatitis B carriers: a pilot, open label, clinical trial in human volunteers. Vaccine. 2010;28:2497-2504.

23. Diao H, Kon S, Iwabuchi K, et al. Osteopontin as a mediator of NKT cell function in T cell-mediated liver diseases. Immunity. 2004; 21:539-550

24. Liu Y, Lu X, Yu HJ, et al. The expression of osteopontin and its association with Clara cell $10 \mathrm{kDa}$ protein in allergic rhinitis. Clin Exp Allergy. 2010;40:1632-1641.

25. Kawamura K, Iyonaga K, Ichiyasu H, Nagano J, Suga M, Sasaki Y. Differentiation, maturation, and survival of dendritic cells by osteopontin regulation. Clin Diagn Lab Immunol. 2005;12:206-212.

26. Shinohara ML, Kim JH, Garcia VA, Cantor H. Engagement of the type I interferon receptor on dendritic cells inhibits T helper 17 cell development: role of intracellular osteopontin. Immunity. 2008;29:68-78.

27. Hardie WD, Korfhagen TR, Sartor MA, et al. Genomic profile of matrix and vasculature remodeling in TGF-alpha induced pulmonary fibrosis. Am J Respir Cell Mol Biol. 2007;37:309-321.

28. Takafuji V, Forgues M, Unsworth E, Goldsmith P, Wang XW. An osteopontin fragment is essential for tumor cell invasion in hepatocellular carcinoma. Oncogene. 2007;26:6361-6371.

29. Xu XW, Lu MH, Tan DM. Association between tumour necrosis factor gene polymorphisms and the clinical types of patients with chronic hepatitis B virus infection. Clin Microbiol Infect. 2005;11:52-56.

30. Sells MA, Chen ML, Acs G. Production of hepatitis B virus particles in Hep G2 cells transfected with cloned hepatitis B virus DNA. Proc Natl Acad Sci U S A. 1987;84:1005-1009.

31. Inaba $\mathrm{K}$, Inaba $\mathrm{M}$, Romani $\mathrm{N}$, et al. Generation of large numbers of dendritic cells from mouse bone marrow cultures supplemented with granulocyte/macrophage colony-stimulating factor. J Exp Med. 1992; 176:1693-1702.

32. Park ES, Park YK, Shin CY, et al. Hepatitis B virus inhibits liver regeneration via epigenetic regulation of urokinase-type plasminogen activator. Hepatology. 2013;58:762-776.
33. Renkl AC, Wussler J, Ahrens T, et al. Osteopontin functionally activates dendritic cells and induces their differentiation toward a Th1-polarizing phenotype. Blood. 2005; 106:946-955.

34. Shinohara ML, Jansson M, Hwang ES, Werneck MB, Glimcher LH, Cantor H. T-bet-dependent expression of osteopontin contributes to T cell polarization. Proc Natl Acad Sci US A. 2005;102:17101-17106.

35. Zhao F, Zhang Y, Wang H, et al. Blockade of osteopontin reduces alloreactive CD8+ T cell-mediated graft-versus-host disease. Blood. 2011; 117:1723-1733.

36. Diao H, Iwabuchi K, Li L, et al. Osteopontin regulates development and function of invariant natural killer T cells. Proc Natl Acad Sci US A. 2008;105:15884-15889.

37. Frikeche J, Simon T, Brissot E, Grégoire M, Gaugler B, Mohty M. Impact of valproic acid on dendritic cells function. Immunobiology. 2012;217:704-710.

38. Löhr HF, Krug S, Herr W, et al. Quantitative and functional analysis of core-specific T-helper cell and CTL activities in acute and chronic hepatitis B. Liver. 1998;18:405-413.

39. Pei J, Tang Z, Zang G, Yu Y. Blockage of Notch1 signaling modulates the T-helper (Th)1/Th2 cell balance in chronic hepatitis B patients. Hepatol Res. 2010;40:799-805.

40. Khan S, Bhargava A, Pathak N, Maudar KK, Varshney S, Mishra PK. Circulating biomarkers and their possible role in pathogenesis of chronic hepatitis B and C viral infections. Indian J Clin Biochem. 2011;26: 161-168.

41. Akbar SK, Horiike N, Onji M. Prognostic importance of antigenpresenting dendritic cells during vaccine therapy in a murine hepatitis B virus carrier. Immunology. 1999;96:98-108.

42. Farag MM, Hoyler B, Encke J, Stremmel W, Weigand K. Dendritic cells can effectively be pulsed by HBVsvp and induce specific immune reactions in mice. Vaccine. 2010;29:200-206.

43. Op den Brouw ML, Binda RS, van Roosmalen MH, et al. Hepatitis B virus surface antigen impairs myeloid dendritic cell function: a possible immune escape mechanism of hepatitis B virus. Immunology. 2009;126:280-289. 


\section{Supplementary materials}
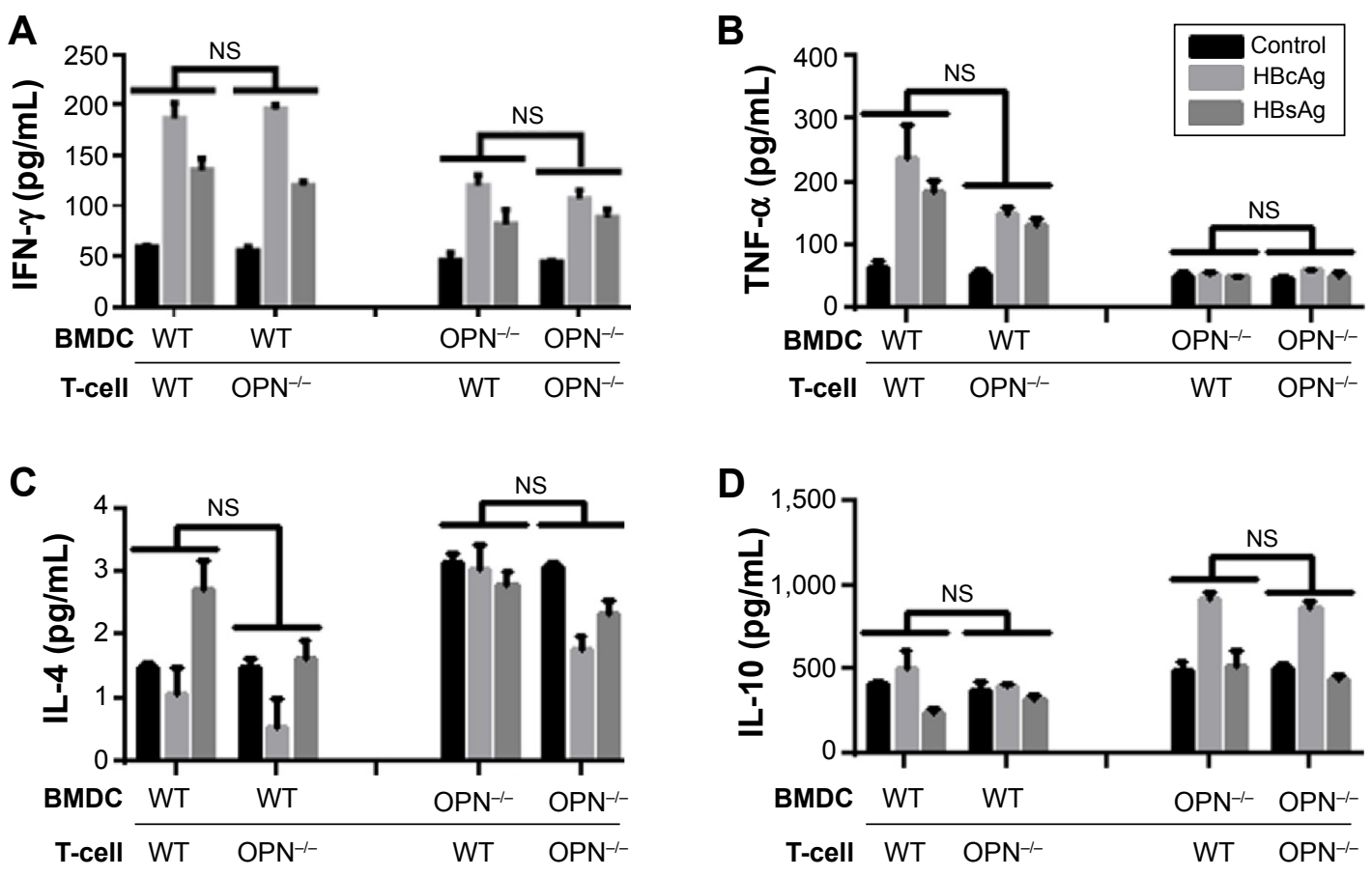

Figure SI OPN deficiency impaired the induction of polarized ThI responses to HBV antigens through DCs.

Notes: T-cells were isolated from the WT and $\mathrm{OPN}^{-1-}$ mice spleen by MACS and cocultured with CDII $\mathrm{c}^{+}$cells isolated from the cell derived from murine BM of WT mice and $\mathrm{OPN}^{-1-}$ mice after HBV antigenic stimulations at a ratio of I0:I, respectively. In addition, the levels of cytokines including IFN- $\gamma(\mathbf{A})$, TNF- $\alpha$ (B), IL-4 (C), and IL-I0 (D) in the coculture supernatants were detected by ELISA.

Abbreviations: OPN, osteopontin; DCs, dendritic cells; HBV, hepatitis B virus; WT, wild-type; BM, bone marrow; BMDC, bone marrow-derived dendritic cell; MACS, magnetically activated cell sorting; IL, interleukin; TNF, tumor necrosis factor; IFN, interferon; NS, no significant difference.

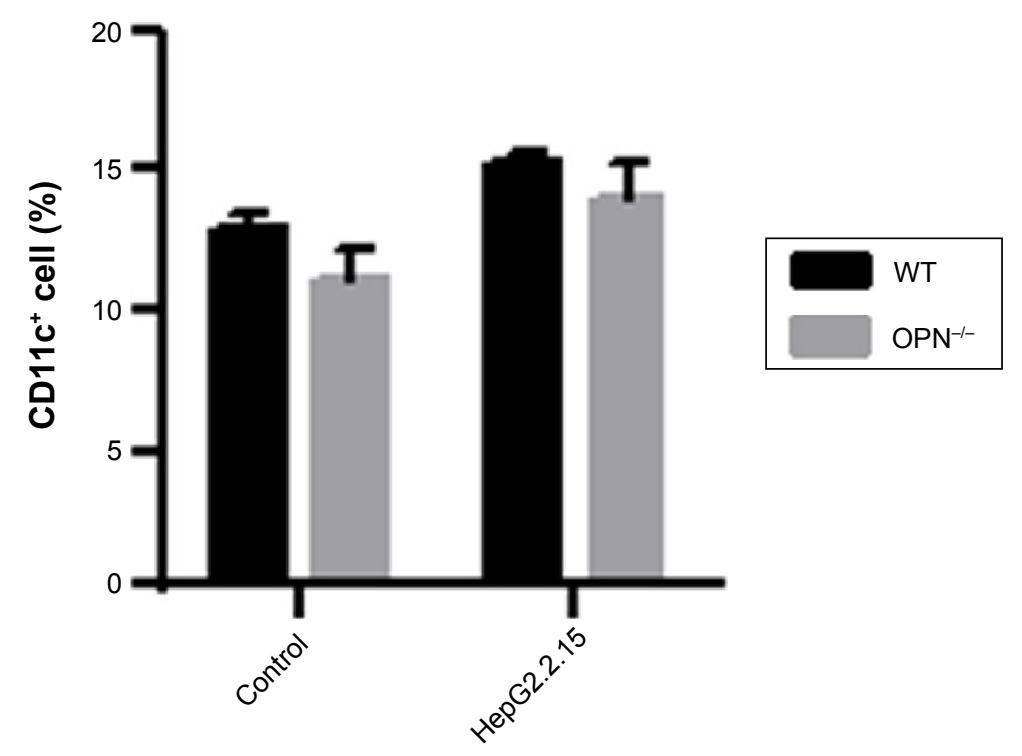

Figure S2 The expression of DCs in liver 24 hours after HepG2.2.15 cell supernatant direct injection into liver.

Abbreviations: OPN, osteopontin; DCs, dendritic cells; WT, wild-type. 
A

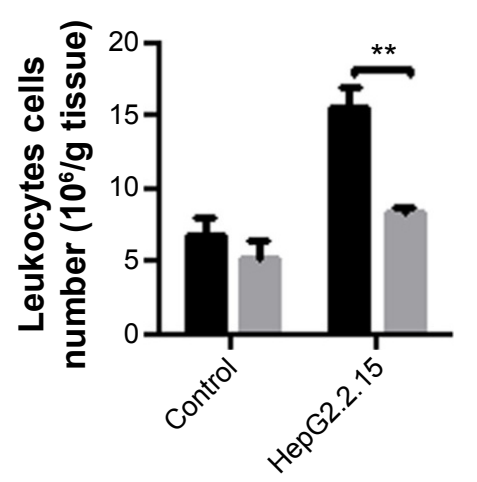

B

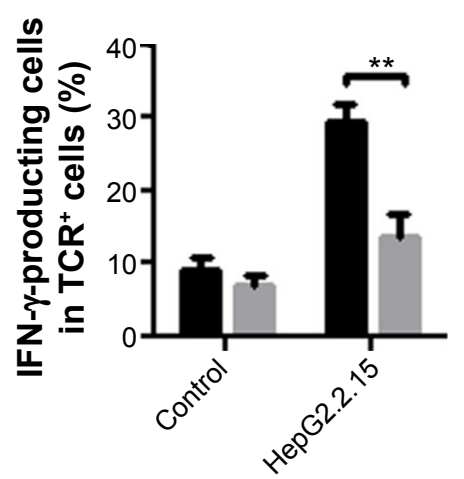

C

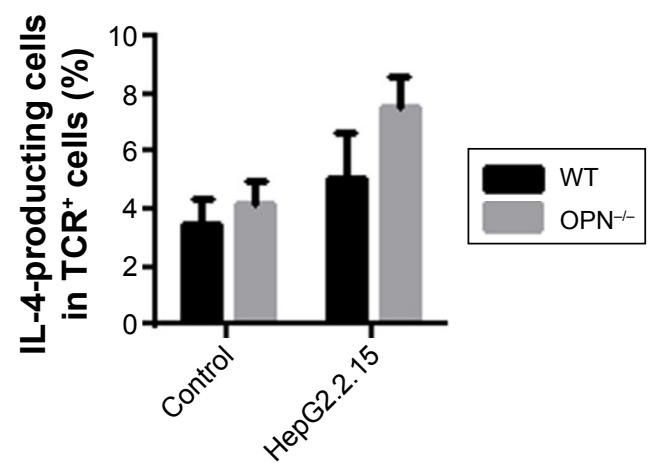

Figure S3 OPN deficiency induced a decrease of inflammatory cell infiltration in liver after HBV antigenic stimulation.

Notes: At 24 hours after hydrodynamic injection of HepG2.2.15 cells culture supernatant, (A) leukocytes number in liver were determined in the OPN ${ }^{-/-}$mice and WT mice; (B) number of IFN- $\gamma$-producing T-cells; and (C) IL-4-producing T-cells were detected in the OPN ${ }^{-1-}$ mice and WT mice, respectively. HepG2 supernatant injection was used as control. $\mathrm{n}=5$ per group. $* * \mathrm{p}<0.01$.

Abbreviations: OPN, osteopontin; HBV, hepatitis B virus; WT, wild-type; IL, interleukin; IFN, interferon; TCR, T-cell receptor.

\section{Publish your work in this journal}

Drug Design, Development and Therapy is an international, peerreviewed open-access journal that spans the spectrum of drug design and development through to clinical applications. Clinical outcomes, patient safety, and programs for the development and effective, safe, and sustained use of medicines are a feature of the journal, which has also been accepted for indexing on PubMed Central. The manuscript management system is completely online and includes a very quick and fair peer-review system, which is all easy to use. Visit http://www.dovepress.com/testimonials.php to read real quotes from published authors. 